\title{
Estrogen receptor 1 mutations in 260 cervical cancer samples from Chinese patients
}

\author{
XIN-MIN YANG ${ }^{1,2}$, ZHI-MIN WU ${ }^{3}$, HUANG HUANG $^{4}$, XIAO-YAN CHU $^{5}$, JUN LOU ${ }^{5}$, \\ LI-XIAN XU ${ }^{1,2}$, YUAN-TING CHEN ${ }^{1,2}$, LI-QUN WANG ${ }^{1,2}$ and OU-PING HUANG ${ }^{1,2}$
}

\author{
${ }^{1}$ College of Medicine, Nanchang University; ${ }^{2}$ Key Laboratory of Women's Reproductive Health of Jiangxi Province, \\ Jiangxi Provincial Maternal and Child Health Hospital, Nanchang, Jiangxi 330006; ${ }^{3}$ Department of Management Engineering, \\ Shangrao Vocational and Technical College, Shangrao, Jiangxi 334109; ${ }^{4}$ Department of Cardiac Surgery, The First \\ Affiliated Hospital, Nanchang University, Nanchang, Jiangxi 330006; ${ }^{5}$ Department of Gynecological Oncology, \\ Jiangxi Provincial Cancer Hospital, Nanchang, Jiangxi 330029, P.R. China
}

Received March 26, 2018; Accepted April 4, 2019

DOI: $10.3892 /$ ol.2019.10612

\begin{abstract}
Cervical cancer is one of the leading causes of cancer-associated mortality among females; however, the underlying molecular mechanisms of its carcinogenesis remain largely unclear. Previous comprehensive genomic studies have revealed prevalent estrogen receptor 1 (ESR1) mutations in breast cancer, which are rare in certain other types of cancer. To the best of our knowledge, it is unknown whether ESR1 mutations also exist in cervical cancer. Considering the evidence that cervical cancer shares certain genetic aberrations with breast cancer, and that the progression of both breast and cervical cancers can be affected by estrogen, it is possible that cervical cancer may also harbor ESR1 mutations. In the present study, a total of 260 Chinese cervical cancer samples with distinct subtypes were tested for the presence of ESR1 mutations. A total of three heterozygous missense ESR1 mutations, p.K303R (c.908A>G), p.T311M (c.932C>T) and p.Y537C (c.1610A $>$ G), were identified in 3/207 (1.4\%) cervical squamous cell carcinoma samples, which were absent in 27 adenosquamous carcinomas and 26 adenocarcinomas samples. Of the three individuals with an ESR1mutation, 1 patient was also diagnosed with ovarian endometriosis and the other 2 patients were diagnosed with a uterine fibroid. A bioinformatics analysis suggested that these ESR1 mutations may be pathogenic by promoting the development of cervical cancer. Furthermore, a previous comprehensive study confirmed that individuals with cervical squamous cell carcinoma possessed ESR1 mutations. These combined studies indicate that ESR1 mutations may participate in the carcinogenesis of cervical
\end{abstract}

Correspondence to: Professor Li-Qun Wang or Professor Ou-Ping Huang, College of Medicine, Nanchang University, 461 Bayi Avenue, Nanchang, Jiangxi 330006, P.R. China

E-mail: 1500325038@qq.com

E-mail: huangouping@gmail.com

Key words: estrogen receptor 1, mutation, cervical cancer, Chinese squamous cell carcinoma, albeit at a low frequency. In conclusion, the present study identified three potentially pathogenic ESR1 mutations in Chinese cervical squamous cell carcinoma samples, but not in other subtypes.

\section{Introduction}

Cervical cancer is one of the leading causes of cancer-associated mortality among females worldwide $(1,2)$. Despite the existence of a safe vaccine against human papillomavirus (HPV) and an early screening test for cervical cancer, the frequency of females undergoing the test is not sufficient $(3,4)$. Furthermore, an insufficient number of HPV vaccines are available in countries that exhibit a high prevalence rate of cervical cancer and the worldwide incidence rate of cervical cancer has not significantly decreased $(5,6)$. Therefore, there is a requirement to explore the underlying molecular mechanisms of cervical cancer.

Estrogen receptor 1 (ESR1) is a transcription factor that can be activated by estrogen and other growth factors in a ligand-dependent manner; activated ESR 1 dimerizes and regulates the transcription of numerous target genes $(7,8)$. Previous comprehensive genomic studies have revealed frequent ESR1 mutations in metastatic types of breast cancer $(9,10)$. Subsequent studies also confirmed these observations (11-13) and demonstrated that ESR1-mutated samples often exhibit increased resistance to aromatase inhibitors (14). In addition, ESR1 mutations have been identified in endometrial (15) and colorectal cancer (16) at low frequencies. However, to the best of our knowledge, it remains unknown whether ESR1 mutations exist in other types of cancer, including cervical cancer.

Cervical cancer shares certain genetic aberrations with breast cancer, including frequent mutations in the PIK3CA, TP53, PTEN and ARID1A genes (17-21), and the development of cervical and breast cancer can be affected by estrogen action (22-25). These similarities suggest that cervical cancer may also harbor ESR1 mutations. To test this hypothesis, a total of 260 samples from Chinese patients with distinct subtypes of cervical cancer were investigated for the presence of ESR1 mutations. A total of three heterozygous missense 
Table I. Primer sequences used for polymerase chain reaction amplification of the estrogen receptor 1 gene.

\begin{tabular}{lllcc}
\hline Exon & \multicolumn{1}{c}{ Forward primer $\left(5^{\prime}-3^{\prime}\right)$} & \multicolumn{1}{c}{ Reverse primer $\left(5^{\prime}-3^{\prime}\right)$} & Annealing temperature $\left({ }^{\circ} \mathrm{C}\right)$ & Amplicon length (bp) \\
\hline $1-1$ & GAGCCTTCTGCCCTGCGG & GGTCTGACCGTAGACCTG & 53 & 270 \\
$1-2$ & CCGCGGCCGCCGCCAACG & GGCGCGGGCGCGGGTAC & 50 & 279 \\
2 & TAATGTTAATGGATTTAC & TTCAACACACTATTACCT & 56 & 242 \\
3 & TAGATTCTGACTGGCTAA & CTGGGAGAGATGTACCTA & 52 & 197 \\
$4-1$ & TGTATAAAAGTTTACACG & GCACTGACCATCTGGTCG & 52 & 253 \\
$4-2$ & TGGCCTTGTCCCTGACG & GTTCTTGAAAAGCTATTG & 58 & 228 \\
5 & TCATTTGAGTCAGCAGG & GCTACAGCCAGGTCACTTA & 58 & 197 \\
6 & TCATGTCTTGTGGAAGA & ATCTTGTGTTATCAACTC & 53 & 226 \\
7 & TCTCACTCTCTCTCTGC & GTAGGAAGCCCACAGAT & 55 & 233 \\
8 & TGTCTTCCCACCTACAG & GGAGCTCTCAGACCGTGG & 57 & 259 \\
\hline
\end{tabular}

ESR1 mutations were identified in 207 samples of cervical squamous cell carcinoma $(3 / 207,1.4 \%)$, whereas no mutations were detected in the 27 adenosquamous carcinoma or 26 adenocarcinomas samples. The identified ESR1 mutations could have predictive values and may provide insights into the diagnosis and molecular therapy of cervical cancer.

\section{Patients and methods}

Formalin-fixed, paraffin-embedded (FFPE) samples. The sample cohort has been previously described (26). Briefly, a total of 260 FFPE cancerous and paired adjacent non-cancerous tissue sections $(10 \mu \mathrm{m})$, including squamous cell carcinoma $(n=207)$, adenosquamous carcinoma $(n=27)$ and adenocarcinoma $(n=26)$ tissues, were fixed in $10 \%$ neutral buffered formalin for $36 \mathrm{~h}$ at room temperature, and collected from the archives of the Department of Pathology at the Jiangxi Provincial Maternal and Child Health Hospital (Nanchang, China) between July 2008 and August 2013. The median age of patients was 43 years old (range, 22-74 years). The present study was approved by the Institutional Review Board of Jiangxi Provincial Maternal and Child Health Hospital (Nanchang, China), and performed according to the Declaration of Helsinki. All patients provided written informed consent prior to the study.

Mutation analysis. Genomic DNA was isolated using QIAamp DNA FFPE Tissue kit (Qiagen GmbH, Hilden, Germany). The entire coding exons and the corresponding intron/exon boundaries of the ESR1 gene were amplified with a set of primer pairs (Table I). The polymerase chain reaction (PCR) amplification was performed in a $50 \mu \mathrm{l}$ reaction volume containing $0.2 \mu \mathrm{M}$ deoxyribonucleotide triphosphate, $5 \mu 1$ 10X PCR buffer, $0.5 \mathrm{U}$ rTaq DNA Polymerase (Takara Biotechnology Co., Ltd., Dalian, China) and 200 ng genomic DNA. PCR amplifications were performed in a Bio-Rad iCycler thermal cycler (Bio-Rad Laboratories, Inc., Hercules, CA, USA) with the following conditions: $94^{\circ} \mathrm{C}$ for $3 \mathrm{~min}, 35$ cycles of $94^{\circ} \mathrm{C}$ for $30 \mathrm{sec}$, $50-58^{\circ} \mathrm{C}$ for $30 \mathrm{sec}$ and $72^{\circ} \mathrm{C}$ for $30 \mathrm{sec}$, and a final extension step at $72^{\circ} \mathrm{C}$ for $10 \mathrm{~min}$. The amplicons were sequenced bidirectionally on an ABI 3730 Genetic Analyzer (Thermo Fisher Scientific, Inc., Waltham, MA, USA) and the sequencing data was aligned against the corresponding genomic sequence
(ESR1, NM_000125) in the National Center for Biotechnology Information (NCBI) database (www.ncbi.nlm.nih.gov). The identified somatic mutations were confirmed by sequencing the paired, adjacent non-cancerous tissues.

In silico analysis of the ESRI mutations. Two online prediction programs, MutationTaster (http://www.mutationtaster. org) (27) and Polymorphism Phenotyping v2 (PolyPhen-2; http://genetics.bwh.harvard.edu/pph2) (28), were used to predict the associations between the identified ESR1 mutations and disease occurrence. These programs assessed the identified ESR1 mutations as either 'benign' or 'pathogenic', according to the automatically predicted score.

Evolutionary conservation analysis. The evolutionary conservation of the mutated amino acids of ESR1 was analyzed in a total of 18 vertebrate species retrieved from the NCBI database, including Homo sapiens (NP_000116), Pan troglodytes (XP_009450519), Mus musculus (NP_001289460), Rattus norvegicus (NP_036821), Ovis aries (NP_000116), Bos taurus (NP_001001443), Gallus gallus (NP_990514), Sus scrofa (NP_999385), Canis lupus familiaris (NP_001273887), Equus caballus (NP_001075241), Tupaia chinensis (NP_001304001), Mustela putorius furo(XP_004753629), Oryctolagus cuniculus (XP_008261925), Pongo abelii (XP_002817538), Coturnix japonica (NP_001310118), Alligator sinensis (XP_014375965), Ceratotherium simum simum (NP_001266182) and Xenopus tropicalis (NP_988866). The Molecular Evolutionary Genetics Analysis 4.0 software (29) was used for multiple sequence alignment.

Protein structure modeling. DeepView Swiss-PdbViewer 4.0 software (30) was used to predict the potential protein structural changes for the identified ESR1 mutations. An available 3D protein structure of human ESR1 (protein data bank code, 2OCF) (31) was retrieved from the SWISS-MODEL repository in the ExPasy web interface (http://www.expasy.org).

\section{Results}

ESR1 mutations. A total of three heterozygous missense ESR1 mutations, p.K303R (c.908A>G), p.T311M (c.932C >T) and p.Y537C (c.1610A>G), were identified from 207 cervical 


\section{p.K303R (c.908A>G)}

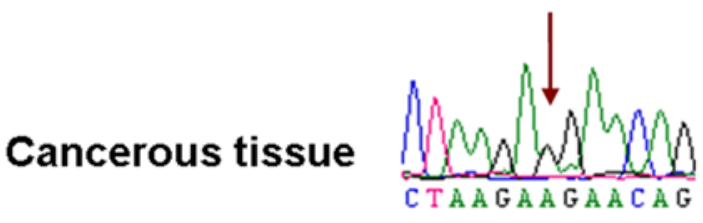

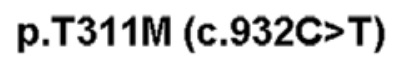
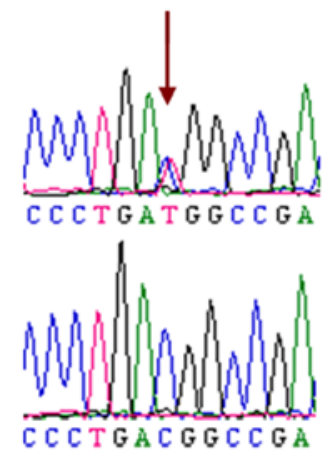

p.Y537C (c.1610A>G)
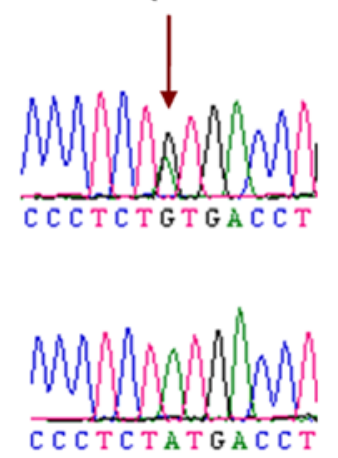

Figure 1. Mutation analysis of the ESR1 gene. Sequencing electropherograms of ESR1 mutations, p.K303R (c.908A>G), p.T311M (c.932C >T) and p.Y537C $(c .1610 \mathrm{~A}>\mathrm{G})$, compared with cervical cancer samples without ESR1 mutations. The arrow indicates the location of the mutation. ESR1, estrogen receptor 1.

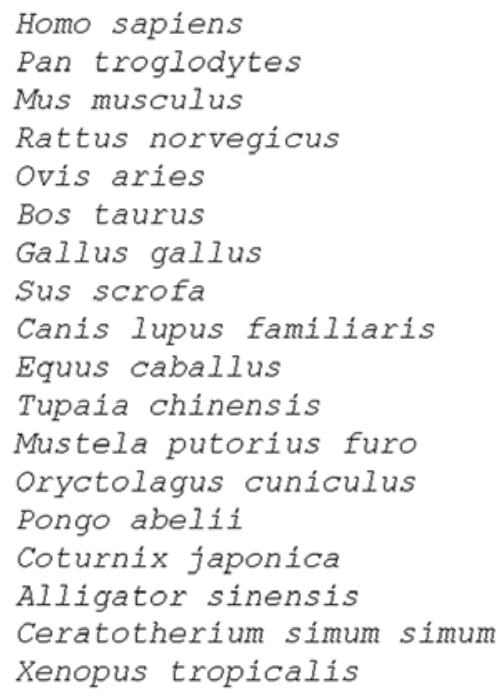

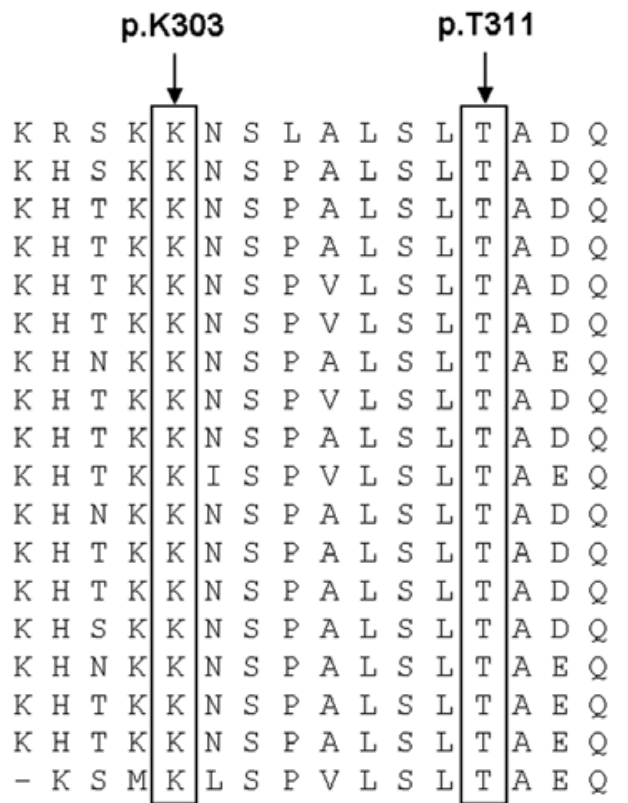

\begin{tabular}{|c|c|c|}
\hline & Y53 & \\
\hline $\begin{array}{lllllll}K & N & V & V & P & L\end{array}$ & & 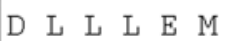 \\
\hline $\begin{array}{lllllll}K & N & V & V & P & L\end{array}$ & $\mathrm{Y}$. & $D$ L L L E M \\
\hline $\begin{array}{lllllll}K & N & V & V & P & L\end{array}$ & $Y$ & $D$ L L L E M \\
\hline $\begin{array}{lllllll}K & N & V & V & P & L\end{array}$ & $Y$ & $D$ L L L E M \\
\hline $\begin{array}{lllllll}K & N & V & V & P & L\end{array}$ & $\mathrm{Y}$. & $D$ L L L E M \\
\hline $\begin{array}{lllllll}K & N & V & V & P & L\end{array}$ & $\mathrm{Y}$. & $D$ L L L E M \\
\hline $\begin{array}{lllllll}K & N & V & V & P & L\end{array}$ & $\mathrm{Y}$ & $D$ L L L E M \\
\hline $\begin{array}{lllllll}K & N & V & V & P & L\end{array}$ & $\mathrm{Y}$. & $D L L L E M$ \\
\hline $\begin{array}{lllllll}K & N & V & V & P & L\end{array}$ & $\mathrm{Y}$. & $D$ L L L E $M$ \\
\hline $\begin{array}{lllllll}K & N & V & V & P & L\end{array}$ & $\mathrm{Y}$. & $D$ L L L E M \\
\hline 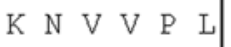 & $\mathrm{Y}$ & $D$ L L L E M \\
\hline $\begin{array}{lllllll}K & N & V & V & P & L\end{array}$ & $\mathrm{Y}$. & $D$ L L L E M \\
\hline $\begin{array}{lllllll}K & N & V & V & P & L\end{array}$ & $\mathrm{Y}$. & $D L L L E M$ \\
\hline 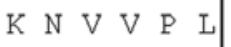 & $\mathrm{Y}$. & $D L L L E M$ \\
\hline $\begin{array}{lllllll}K & N & V & V & P & L\end{array}$ & $\mathrm{Y}$. & $D$ L L L E M \\
\hline $\begin{array}{lllllll}K & N & V & V & P & L\end{array}$ & $\mathrm{Y}$. & $D L L L E M$ \\
\hline $\begin{array}{lllllll}K & N & V & V & P & L\end{array}$ & $\mathrm{Y}$. & $D$ L L L E M \\
\hline 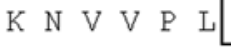 & $\mathrm{Y}$ & $D L L L E M$ \\
\hline
\end{tabular}

Figure 2. Evolutionary conservation analysis of ESR1 mutations (p.K303R, p.T311M and p.Y537C). Amino acid sequences of the ESR1 protein in 18 vertebrate species were aligned using Molecular Evolutionary Genetics Analysis software. ESR1, estrogen receptor 1.

squamous cell carcinoma samples $(3 / 207,1.4 \%)$, while no mutations were detected in the adenosquamous carcinoma and adenocarcinoma samples. The mutations were absent in the paired non-cancerous tissues and were therefore considered to be somatic (Fig. 1). The K303R and T311M mutations are located in the 'hingeregion' and the Y537C mutation is located in the 'ligand-binding domain' $(9,10)$. Of the three individuals with ESR1 mutations, two were further diagnosed with uterine fibroid and one with ovarian endometriosis.

In silico analysis of the ESR1 mutations. Two publicly available bioinformatics programs, MutationTaster and PolyPhen-2, were used to predict the potential functional significance of the ESR1 mutations. The predictions by MutationTaster for the three ESR1 mutations (p.K303R, p.T311M and p.Y537C) were 'disease causing' and 'protein features (might be) affected', while PolyPhen-2 predicted these mutations to be 'probably damaging' (p.T311M and p.Y537C) or 'possibly damaging'
(p.K303R), with a prediction score of $>0.90$. Furthermore, the Y537C (c.1610A>G) and K303R (c.908A>G) mutations were not identified in the 1,000Genomes (https://www.ncbi. nlm.nih.gov/variation/tools/1000genomes/) (32) or the Exome Aggregation Consortium (EXAC; http://exac.broadinstitute. org/) (33) databases, while the p.T311M (c.932C>T) mutation was identified in the general population with an extremely low frequency $(1 / 121,362)$ in the EXAC database.

Evolutionary conservation analysis and protein structural modeling. The results of evolutionary conservation analysis demonstrated that the three ESR1 mutations were associated with highly conserved amino acid changes among 18 vertebrate species, ranging from Homo sapiens to Xenopus tropicalis (Fig. 2). The protein structural prediction results suggested that the three ESR1 mutations may induce the structural changes in the side chain of ESR1 protein (Fig. 3); results that were consistent with the prediction results by MutationTaster. 


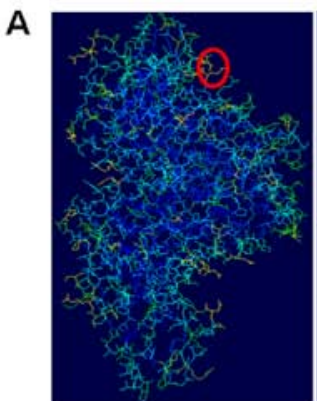

WT

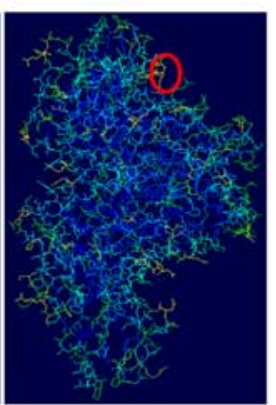

K303R

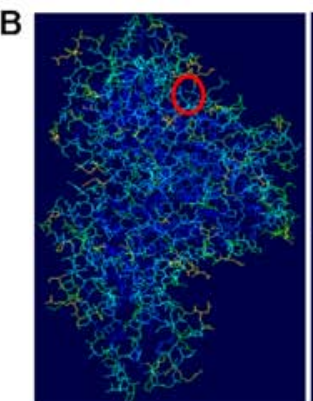

WT

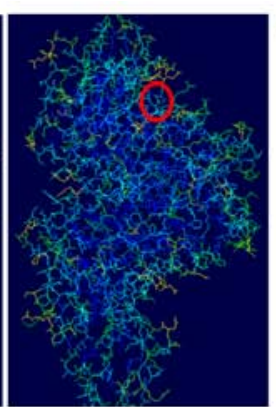

T311M

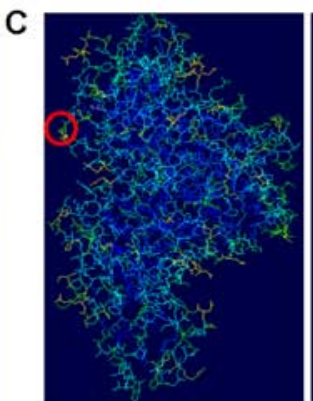

WT

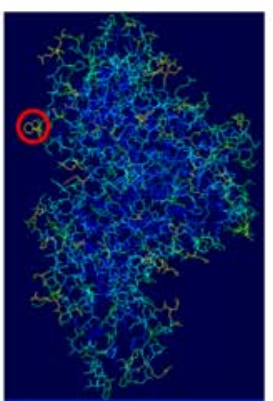

Y537C

Figure 3. Structural differences between WT ESR1 and three ESR1 mutants. Protein structural modeling of human WT ESR1 and ESR1 with (A) p.K303R, (B) p.T311M and (C) p.Y537C mutations. The red circles indicated the regions of ESR1 structural changes caused by the three ESR1 mutations. This analysis was performed using DeepView Swiss-PdbViewer 4.0 software based on the 3D structure of human ESR1 protein (protein data bank code, 2OCF). ESR1, estrogen receptor 1; WT, wild-type.

\section{Discussion}

Previous studies have identified prevalent ESR1 mutations in breast cancer $(9,10)$; however, it remains largely unknown whether ESR1 mutations exist in other types of cancer, including cervical cancer.

In the present study, a total of 260 samples from Chinese patients with distinct subtypes of cervical cancer were tested for the presence of ESR1 mutations. In total, three missense somatic mutations in ESR1, p.K303R (c.908A $>$ G), p.T311M (c.932C $>$ T) and p.Y537C (c.1610A $>$ G), were identified from 207 squamous cell carcinomas $(3 / 207,1.4 \%)$, which were not present in other cervical cancer subtypes. Evolutionary conservation analysis demonstrated that the three ESR1 mutations were associated with highly conserved amino acid, which may describe the potential to cause protein structural changes. In silico analysis suggested that these mutations may be pathogenic. Furthermore, the three ESR1 mutations have previously been identified in other types of cancer. The p.K303R (c.908A $>$ G) mutation has been observed in 206/6,556 samples of breast cancer (24-37). The p.T311M (c.932C $>$ T) mutation has been identified in $2 / 2,218$ colorectal cancer samples (38) and $1 / 2,105$ liver cancer samples (38). In addition, the p.Y537C (c.1610A $>$ G) mutation has been detected in 10/6,556 breast cancer samples (11,39-41). Similarly, a previous comprehensive study identified ESR1 somatic mutations p.K206R (c.617A $>$ G) and p.L372L (c.1116C>G) in 2/306 (0.7\%) cervical squamous cell carcinoma samples (http://cancer.sanger.ac.uk/cosmic). However, a previous genomic analysis of cervical cancer failed to detect any ESR1 mutations in 79 squamous cell carcinoma samples (17). Considering the low frequency of ESR1 mutation in cervical squamous cell carcinoma, it is suggested that the small sample size analyzed in this previous study may have caused the inconsistency in the results (17). In combination, both previous studies and the present study suggest that ESR1 mutations may participate in the carcinogenesis of cervical cancer, albeit at a low frequency.

A number of previous functional assays for the identified ESR1 mutations, including p.K303R (42) and p.Y537C (9,43), demonstrated that these mutations are associated with acquired endocrine resistance in hormonal therapy in breast cancer $(7,8,40,41)$. Therefore, it is proposed that the ESR1 mutations identified in cervical cancer in the present study may further cause acquired endocrine resistance to hormonal therapy in breast cancer.

Antihormonal agents have recently been used to improve effects of chemo- and radiotherapy in cervical cancer (44). However, due to the potential acquired endocrine resistance in cervical cancer samples with ESR1 mutations, antihormonal agents should be used with caution during chemo-and radiotherapy.

The three ESR1 mutations were not detected in the 27 adenosquamous carcinoma or the 26 adenocarcinoma samples of the present study, which is consistent with a prior genomic analysis of cervical cancer with distinct subtypes, in which no ESR1 mutations were detected in either 24 adenocarcinoma or 7 adenosquamous carcinoma samples (17). In summary, these results suggest that the ESR1 mutations may not be positively involved in the pathogenesis of cervical adenocarcinoma and adenosquamous carcinoma. However, the absence of ESR1 mutations in patients with adenosquamous carcinoma and adenocarcinoma may be due to the small sample sizes analyzed in the present study.

In conclusion, the current study identified three potentially pathogenic ESR1 mutations in cervical squamous cell carcinoma samples from Chinese patients, which were not observed in other subtypes. These results, together with numerous previous studies, suggested that ESR1 mutations may be involved in the carcinogenesis of squamous cell carcinoma, but not in other subtypes of cervical cancer.

\section{Acknowledgements}

Not applicable.

\section{Funding}

The present study was supported by grants from the Natural Science Foundation of China (grant no. 81160079) and the Natural Science Foundation of Jiangxi Province (grant nos. 20143ACG70016 and 20161ACB21021).

\section{Availability of data and materials}

All the data generated or analyzed during the present study are available from the corresponding author on reasonable request. 


\section{Authors' contributions}

XMY, HH, LXX and YTC performed the experiments. ZMW and LQW analyzed the data. XYC and JL collected samples and clinical data. XMY prepared the manuscript. OPH designed the study and revised the manuscript.

\section{Ethics approval and consent to participate}

The experimental protocol was established according to the ethical guidelines of the Helsinki Declaration and was approved by the Human Ethics Committee of Nanchang University. Written informed consent was obtained from all participants or their guardian.

\section{Patients consent for publication}

Not applicable.

\section{Competing interests}

The authors declare that they have no competing interests.

\section{References}

1. Siegel RL, Miller KD and Jemal A: Cancer statistics, 2018. CA Cancer J Clin 68: 7-30, 2018.

2. Jemal A, Simard EP, Dorell C, Noone AM, Markowitz LE, Kohler B, Eheman C, Saraiya M, Bandi P, Saslow D, et al: Annual report to the nation on the status of cancer, 1975-2009, featuring the burden and trends in human papillomavirus (HPV)-associated cancers and HPV vaccination coverage levels. J Natl Cancer Inst 105: 175-201, 2013.

3. Pedersen K, Burger EA, Nygård M, Kristiansen IS and Kim JJ: Adapting cervical cancer screening for women vaccinated against human papillomavirus infections: The value of stratifying guidelines. Eur J Cancer 91: 68-75, 2018.

4. Philp L, Jembere N, Wang L, Gao J, Maguire B and Kupets R: Pap tests in the diagnosis of cervical cancer: Help or hinder? Gynecol Oncol 150: 61-66, 2018.

5. Bogani G, Leone Roberti Maggiore U, Signorelli M, Martinelli F, Ditto A, Sabatucci I, Mosca L, Lorusso D and Raspagliesi F: The role of human papillomavirus vaccines in cervical cancer: Prevention and treatment. Crit Rev Oncol Hematol 122: 92-97, 2018

6. Lytwyn A, Elit L and Sellors JW: Human papillomavirus DNA versus papanicolaou screening tests for cervical cancer. N Engl J Med 358: 641, 2008.

7. Yaşar P, Ayaz G, User SD, Güpür G and Muyan M: Molecular mechanism of estrogen-estrogen receptor signaling. Reprod Med Biol 16: 4-20, 2016.

8. Bado I, Gugala Z, Fuqua SAW and Zhang XH: Estrogen receptors in breast and bone: From virtue of remodeling to vileness of metastasis. Oncogene 36: 4527-4537, 2017.

9. Robinson DR, Wu YM, Vats P, Su F, Lonigro RJ, Cao X, Kalyana-Sundaram S, Wang R, Ning Y, Hodges L, et al: Activating ESR1 mutations in hormone-resistant metastatic breast cancer. Nat Genet 45: 1446-1451, 2013.

10. Toy W, Shen Y, Won H, Green B, Sakr RA, Will M, Li Z, Gala K, Fanning S, King TA, et al: ESR1 ligand-binding domain mutations in hormone-resistant breast cancer. Nat Genet 45: 1439-1445, 2013.

11. Bartels S, Christgen M, Luft A, Persing S, Jödecke K, Lehmann U and Kreipe $\mathrm{H}$ : Estrogen receptor (ESR1) mutation in bone metastases from breast cancer. Mod Pathol 31: 56-61, 2018.

12. Yanagawa T, Kagara N, Miyake T, Tanei T, Naoi Y, Shimoda M, Shimazu K, Kim SJ and Noguchi S: Detection of ESR1 mutations in plasma and tumors from metastatic breast cancer patients using next-generation sequencing. Breast Cancer Res Treat 163: 231-240, 2017.

13. Lefebvre C, Bachelot T, Filleron T, Pedrero M, Campone M, Soria JC, Massard C, Lévy C, Arnedos M, Lacroix-Triki M, et al: Mutational profile of metastatic breast cancers: A retrospective analysis. PLoS Med 13: e1002201, 2016.
14. Clarke R, Tyson JJ and Dixon JM: Endocrine resistance in breast cancer-An overview and update. Mol Cell Endocrinol 418: 220-234, 2015.

15. Backes FJ, Walker CJ, Goodfellow PJ, Hade EM, Agarwal G, Mutch D, Cohn DE and Suarez AA: Estrogen receptor-alpha as a predictive biomarker in endometrioid endometrial cancer. Gynecol Oncol 141: 312-317, 2016.

16. Cancer Genome Atlas Network; Muzny DM, Bainbridge MN, Chang K, Dinh HH, Drummond JA, Fowler G, Kovar CL, Lewis LR, Morgan MB, et al: Comprehensive molecular characterization of human colon and rectal cancer. Nature 487: 330-337, 2012.

17. Ojesina AI, Lichtenstein L, Freeman SS, Pedamallu CS, Imaz-Rosshandler I, Pugh TJ, Cherniack AD, Ambrogio L, Cibulskis K, Bertelsen B, et al: Landscape of genomic alterations in cervical carcinomas. Nature 506: 371-375, 2014.

18. Muller E, Brault B, Holmes A, Legros A, Jeannot E, Campitelli M, Rousselin A, Goardon N, Frébourg T, Krieger S, et al: Genetic profiles of cervical tumors by high-throughput sequencing for personalized medical care. Cancer Med 4: 1484-1493, 2015.

19. Sjöblom T, Jones S, Wood LD, Parsons DW, Lin J, Barber TD, Mandelker D, Leary RJ, Ptak J, Silliman N, et al: The consensus coding sequences of human breast and colorectal cancers. Science 314: 268-274, 2006.

20. Banerji S, Cibulskis K, Rangel-Escareno C, Brown KK, Carter SL, Frederick AM, Lawrence MS, Sivachenko AY, Sougnez C, Zou L, et al: Sequence analysis of mutations and translocations across breast cancer subtypes. Nature 486: 405-409, 2012.

21. Cancer Genome Atlas Research Network; Albert Einstein College of Medicine; Analytical Biological Services; Barretos Cancer Hospital; Baylor College of Medicine; Beckman Research Institute of City of Hope; Buck Institute for Research on Aging; Canada's Michael Smith Genome Sciences Centre; Harvard Medical School; Helen F. Graham Cancer Center \& Research Institute at Christiana Care Health Services, et al: Integrated genomic and molecular characterization of cervical cancer. Nature 543: 378-384, 2017.

22. den Boon JA, Pyeon D, Wang SS, Horswill M, Schiffman M, Sherman M, Zuna RE, Wang Z, Hewitt SM, Pearson R, et al: Molecular transitions from papillomavirus infection to cervical precancer and cancer: Role of stromal estrogen receptor signaling. Proc Natl Acad Sci USA 112: E3255-E3264, 2015.

23. Bronowicka-Kłys DE, Lianeri M and Jagodziński PP: The role and impact of estrogens and xenoestrogen on the development of cervical cancer. Biomed Pharmacother 84: 1945-1953, 2016.

24. Leung YK, Lee MT, Lam HM, Tarapore P and Ho SM: Estrogen receptor-beta and breast cancer: Translating biology into clinical practice. Steroids 77: 727-737, 2012.

25. Vazquez Rodriguez G, Abrahamsson A, Jensen LD and Dabrosin C: Estradiol promotes breast cancer cell migration via recruitment and activation of neutrophils. Cancer Immunol Res 5: 234-247, 2017.

26. Zou Y, Liu FY, Wu J, Wan L, Fang SF, Zhang ZY, Luo Y, Chen MH, Huang MZ, He M and Huang OP: Mutational analysis of the RAS/RAF/MEK/ERK signaling pathway in 260 Han Chinese patients with cervical carcinoma. Oncol Lett 14: 2427-2431, 2017.

27. Schwarz JM, Cooper DN, Schuelke M and Seelow D: MutationTaster2: Mutation prediction for the deep-sequencing age. Nat Methods 11: 361-362, 2014.

28. Adzhubei IA, Schmidt S, Peshkin L, Ramensky VE, Gerasimova A, Bork P, Kondrashov AS and Sunyaev SR: A method and server for predicting damaging missense mutations. Nat Methods 7: 248-249, 2010.

29. Tamura K, Dudley J, Nei M and Kumar S: MEGA4: Molecular evolutionary genetics analysis (MEGA) software version 4.0. Mol Biol Evol 24: 1596-1599, 2007.

30. Johansson MU, Zoete V, Michielin O and Guex N: Defining and searching for structural motifs using DeepView/Swiss-PdbViewer. BMC Bioinformatics 13: 173, 2012.

31. Koide A, Abbatiello S, Rothgery L and Koide S: Probing protein conformational changes in living cells by using designer binding proteins: Application to the estrogen receptor. Proc Natl Acad Sci USA 99: 1253-1258, 2002.

32. 1000 Genomes Project Consortium; Abecasis GR, Auton A, Brooks LD, DePristo MA, Durbin RM, Handsaker RE, Kang HM, Marth GT and McVean GA: An integrated map of genetic variation from 1,092 human genomes. Nature 491: 56-65, 2012. 
33. Lek M, Karczewski KJ, Minikel EV, Samocha KE, Banks E, Fennell T, O'Donnell-Luria AH, Ware JS, Hill AJ, Cummings BB, et al: Analysis of protein-coding genetic variation in 60,706 humans. Nature 536: 285-291, 2016.

34. Fuqua SA, Wiltschke C, Zhang QX, Borg A, Castles CG Friedrichs WE, Hopp T, Hilsenbeck S, Mohsin S, O'Connell P and Allred DC: A hypersensitive estrogen receptor-alpha mutation in premalignant breast lesions. Cancer Res 60: 4026-4029, 2000.

35. Conway K, Parrish E, Edmiston SN, Tolbert D, Tse CK, Geradts J, Livasy CA, Singh H, Newman B and Millikan RC: The estrogen receptor-alpha A908G (K303R) mutation occurs at a low frequency in invasive breast tumors: Results from a population-based study. Breast Cancer Res 7: R871-R880, 2005.

36. Herynk MH, Parra I, Cui Y, Beyer A, Wu MF, Hilsenbeck SG and Fuqua SA: Association between the estrogen receptor alpha A908G mutation and outcomes in invasive breast cancer. Clin Cancer Res 13: 3235-3243, 2007.

37. Abbasi S, Rasouli M, Nouri M and Kalbasi S: Association of estrogen receptor- $\alpha$ A908G (K303R) mutation with breast cancer risk. Int J Clin Exp Med 6: 39-49, 2013.

38. Lim B, Mun J, Kim JH, Kim CW, Roh SA, Cho DH, Kim YS, Kim SY and Kim JC: Genome-wide mutation profiles of colorectal tumors and associated liver metastases at the exome and transcriptome levels. Oncotarget 6: 22179-22190, 2015.

39. Wang P, Bahreini A, Gyanchandani R, Lucas PC, Hartmaier RJ, Watters RJ, Jonnalagadda AR, Trejo Bittar HE, Berg A, Hamilton RL, et al: Sensitive detection of mono- and polyclonal ESR1 mutations in primary tumors, metastatic lesions, and cell-free DNA of breast cancer patients. Clin Cancer Res 22: 1130-1137, 2016.
40. Niu J, Andres G, Kramer K, Kundranda MN, Alvarez RH, Klimant E, Parikh AR, Tan B, Staren ED and Markman M: Incidence and clinical significance of ESR1 mutations in heavily pretreated metastatic breast cancer patients. Onco Targets Ther 8: 3323-3328, 2015.

41. Takeshita T, Yamamoto Y, Yamamoto-Ibusuki M, Inao T, Sueta A, Fujiwara S, Omoto Y and Iwase H: Droplet digital polymerase chain reaction assay for screening of ESR1 mutations in 325 breast cancer specimens. Transl Res 166: 540-553.e2, 2015.

42. Cui Y, Zhang M, Pestell R, Curran EM, Welshons WV and Fuqua SA: Phosphorylation of estrogen receptor alpha blocks its acetylation and regulates estrogen sensitivity. Cancer Res 64: 9199-9208, 2004.

43. Toy W, Weir H, Razavi P, Lawson M, Goeppert AU, Mazzola AM, Smith A, Wilson J, Morrow C, Wong WL, et al: Activating ESR1 mutations differentially affect the efficacy of ER antagonists. Cancer Discov 7: 277-287, 2017.

44. Segovia-Mendoza M, Jurado R, Mir R, Medina LA, Prado-Garcia H and Garcia-Lopez P: Antihormonal agents as a strategy to improve the effect of chemo-radiation in cervical cancer: In vitro and in vivo study. BMC Cancer 15: 21, 2015.

This work is licensed under a Creative Commons

Attribution-NonCommercial-NoDerivatives 4.0 International (CC BY-NC-ND 4.0) License. 